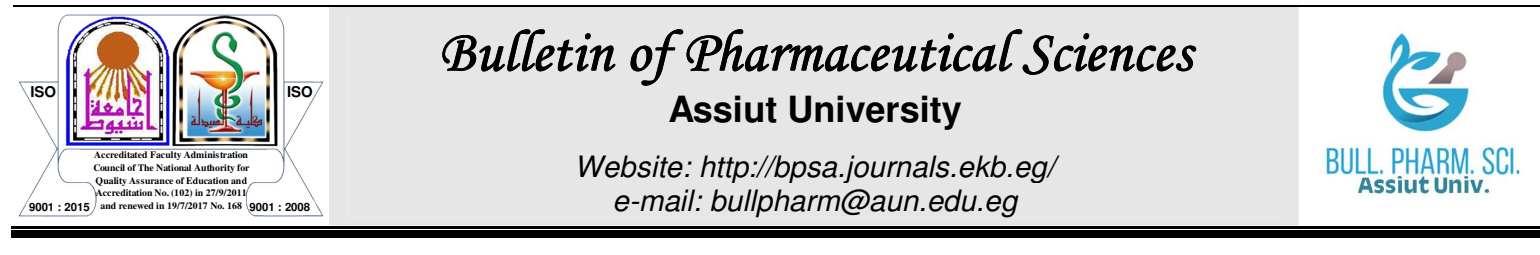

\title{
PHARMACOKINETIC SIMULATION AND OPTIMIZING GENTAMICIN DOSING IN PEDIATRICS
}

\author{
Ahmed S. Ali ${ }^{1,2^{*}}$ \\ ${ }^{1}$ Department of Pharmaceutics, Faculty of Pharmacy, Assiut University, Assiut, Egypt \\ ${ }^{2}$ Department of Pharmacology, Faculty of Medicine, King Abdulaziz University, KSA
}

\begin{abstract}
Aim: This study was conducted to optimize gentamicin (genta) use in paediatrics incorporating the estimation of serum drug concentrations and customized pharmacokinetic (PK) simulations. Method: 66 patients (age 1-144 month) were enrolled in the study. They received gentamicin 2$2.5 \mathrm{mg} / \mathrm{kg}$ every $8 \mathrm{hr}$. (TID regimen). Serum genta concentrations within one dosing interval of dose 3 and dose 4 were determined using an immunoassay; blood samples were collected at 30 minutes after the end of infusion while a trough level sample was collected just before the next dose. Customized PK simulation analysis was based on the following assumptions: Singlecompartment model, first-order elimination, and repeated short time IV infusion. PK parameters and simulation of genta peak/trough levels after various regimens were estimated and compared statistically. Results: About 65\% of the patients showed subtherapeutic peak genta levels (less than $6 \mathrm{ug} / \mathrm{ml}$ ) during the dosing intervals. Potentially toxic trough levels (>1 ug/ml) were observed in two patients. Neonates (1-12 months) showed a relatively higher mean genta volume of distribution (Vd), $0.51 \pm 0.18 \mathrm{~L} / \mathrm{Kg}$, vs $0.37 \pm 0.13(p<0.05)$ in children $(>1-12 \mathrm{y})$. Half-life in both groups was comparable (about $3 \mathrm{~h}$ ). Simulation suggests BID regimens will provide the best theoretically overall peak/trough targets. Discussion: In children, a higher volume of distribution of genta could be associated with the lower serum peak levels due to the conventional dosing regimen (TID). Conclusion: Optimal dosing regimen in pediatric patients can be designed to achieve target high peak, low trough levels based on simplified customized $P K$ simulations.
\end{abstract}

\section{INTRODUCTION}

Aminoglycosides (AG) are bactericidal antibiotics, of which genta is frequently used for the management of many serious gramnegative infections in adults, children, and neonates. However, it needs to be emphasized that their use is associated with the dilemma of nephrotoxicity and ototoxicity ${ }^{1}$. Distinctly, this is surmounted to a great extent by, therapeutic drug monitoring (TDM) to ensure efficacy and minimize toxicities ${ }^{2-5}$. Interestingly; AG significantly revealed concentration-dependent efficacy, the post-antibiotic effect that supports adopting once daily (OD) dosing in adults ${ }^{6}$. Nevertheless, a considerable dispute has been expressed regarding the effectiveness of oncedaily dosing of AG in children. A cohort study has revealed a higher incidence of ototoxicity following the $\mathrm{OD}$ regimen of $\mathrm{AG}$ in children associated with risk factors ${ }^{7}$. The analogous finding was convincingly reported in other studies utilizing AG in critically ill paediatrics ${ }^{8}$ and those suffering from cystic fibrosis ${ }^{9}$. The present work aimed to provide a simple approach to optimize the dosing of genta in children with normal renal function.

\section{METHODS}

The present prospective study was implemented at the pediatric department, King Abdulaziz University Hospital (KAUH), Jeddah, KSA. The study protocol was approved by the Research Ethics Committee of the Faculty of Medicine, KAUH. 


\section{Inclusion Criteria}

Neonates aged 1-12 m, children 13-144 m who received genta as an empirical treatment for gram-negative infections, were included in the study. Monitoring of genta level was a part of routine clinical care at KAUH. The guidelines for genta dosing allow a range of doses given the diversity of pathogens, severity of infections and patients characteristics ${ }^{10}$. The dosing regimen is the sole responsibility of the clinician in charge.

According to the FDA guidance (1998), the pediatric population are classified as: neonates (birth to 1 month), infants (1 month to 2 years), developing children (2-12 years), and adolescents (12-16 years) ${ }^{11}$. The present study focusses on, developing children, we will use the term (Children) throughout this article.

\section{The exclusion criteria}

Those patients who had missing peak or trough levels; and those who received drugs that impair renal function or have congenital anomalies. Furthermore, relevant demographic, renal function test, co-medications, dosing regimen, and sampling time of genta, were retrieved from patients' files.

In the present study, the TID regimen (2$2.5 \mathrm{mg} / \mathrm{kg}$; every $8 \mathrm{hr}$.) was implemented.

Samples for the peak (Cmax) genta level were taken after the $3^{\text {rd }}$ dose; 30 minutes after the end of infusion (post-distribution phase) and the samples for trough level $\left(\mathrm{C}_{\min }\right)$ were taken 10-15 min before the fourth dose.

Also, the genta level was analyzed by a fully-automated immunoassay procedure using a homogenous particle enhanced turbidimetric inhibitory immunoassay technique (PETUNIA) with Dimension Clinical Chemistry System (Stream lab - Dad Behring). Calibration and analysis were performed as specified by the reagent manufacturer. All specimens were tested within a few hours. Accuracy of analysis was assured by the daily running of three levels of quality control samples (QC). The coefficient of variation was less than $5 \%$.

\section{PK analysis}

An Excel-based program was developed (Excel 2016 and visual basic) to estimate the volume of distribution $(\mathrm{Vd})$, elimination rate constant (k), and half-life. The estimated PK parameters were used for simulation of concentration vs time profile of assumed dosing regimen and minimum inhibitory concentration (MIC) of $1 \mathrm{ug} / \mathrm{ml}$. (supplementary material). The simulation aims to visually demonstrate achievement of the therapeutic peak; defined as 8-10 times MIC, therapeutic trough $<1 \mathrm{ug} / \mathrm{ml}$. The low or undetectable level should not exceed $8 \mathrm{hrs}$ (the acceptable time of the post-antibiotic effect of gentamicin) $)^{12}$.

The principles of estimation assumed that; genta distribution follows a one-compartment model and it was eliminated by the $1^{\text {st }}$ order kinetic process (equations 1-5) ${ }^{7 \& 13}$.

\section{Estimation of elimination rate constant (K)}

$$
K\left(h r^{-1}\right)=\frac{\ln \ln \left(\frac{C_{1}}{C_{2}}\right)}{t_{2}-t_{1}}
$$

$\mathrm{C}_{1}=$ peak level $(0.5 \mathrm{hr}$. after the end of infusion), $C_{2}=$ pre-dose or trough level, $\left(t_{2}-t_{1}\right)$ $=$ Time difference between the two samples.

For practical purposes Css was assumed to be attained after 3 doses, i.e., in our study, the samples were taken after the $3^{\text {rd }}$ dose $\&$ before the $4^{\text {th }}$ dose).

Estimate half-life $\left(t_{1 / 2}\right) \&$ Elimination rate constant (K)

$K=\frac{0.694}{t_{1 / 2}}$

Estimation of $\mathrm{Vd}(\mathrm{L} / \mathrm{kg})$

$V d\left(\frac{L}{K g}\right)=\frac{D\left(1-e^{-K t_{i}}\right)}{K \times t_{i}\left[C_{1}-\left(C_{2} \times e^{-K t_{2}}\right)\right]}$

$\mathrm{D}=$ Dose of genta $(\mathrm{mg} / \mathrm{kg}) ; \mathrm{ti}=$ infusion time (0.5 hr.), e= base for Ln.; $t_{2}=$ time of the $2^{\text {nd }}$ sample (trough).

\section{Prediction of genta level at any time post-} dose

$$
\left(C_{1}\right)=\frac{D \times\left(1-e^{K t_{i}}\right)}{K \times V d \times t_{i}} \times \frac{1}{1-\left(e^{-K \mathrm{~T}}\right)}
$$

$\mathrm{T}(\mathrm{tau})=$ dosing interval $(\mathrm{hr}$.

$C_{x}=C_{1} \times e^{-K t_{x}}$

$\mathrm{t}_{\mathrm{x}}$ : sampling time for $\mathrm{C}_{2},(\mathrm{x}$ hr. post-dose $)$. 


\section{Statistical analysis}

Statistical analysis was performed using a statistical package program (SPSS, version 22). Pharmacokinetic parameters are presented as the means \pm standard deviation $(\mathrm{M} \pm \mathrm{SD})$ independent sample t-test two-tailed, was used to compare mean PK values, $p<0.05$ was considered as significant.

\section{RESULTS AND DISCUSSION}

\section{Results}

In this study, sixty-six pediatric patients were enrolled prospectively. Demographic and relevant clinical data are summarized in tables 1\&2. Notably, chest infection represented a major reason for treatment with genta followed by the post-surgical procedure.

Table 1: Demographics; genta dose and baseline serum creatinine of pediatric patients $(n=66)$.

\begin{tabular}{||c|c|c|c|}
\hline & & Children & Infants \\
\hline \multirow{3}{*}{ Age (month) } & Mean & 53 & 1.9 \\
\cline { 2 - 4 } & SD & 39.7 & 1.7 \\
\cline { 2 - 4 } & Range & $13-144$ & $1-6$ \\
\hline \multirow{3}{*}{ Weight (Kg) } & Mean & 15.7 & 4.1 \\
\cline { 2 - 4 } & SD & 13 & 0.58 \\
\cline { 2 - 4 } & Range & $6.2-60$ & $2-3.2$ \\
\hline \multirow{2}{*}{$\begin{array}{c}\text { Dose } \\
\text { mg/kg/8 hr. }\end{array}$} & Mean & 2.2 & 2.47 \\
\cline { 2 - 4 } & SD & 0.46 & 1.1 \\
\cline { 2 - 4 } $\begin{array}{c}\text { Basle serum } \\
\text { creatinine } \\
\text { Mmol/L }\end{array}$ & Range & $1-2.9$ & $2-3.2$ \\
\cline { 2 - 4 } & Mean & 34.7 & 33.5 \\
\cline { 2 - 4 } & Range & $28-45$ & $24-43$ \\
\hline \hline
\end{tabular}

Table 2: Indication of genta and concomitant antibiotics in pediatric patients $(n=66)$.

\begin{tabular}{||l|l|c|c||}
\hline \multirow{7}{*}{ Disease } & & $\begin{array}{c}\text { No of } \\
\text { patients }\end{array}$ & $\%$ \\
\hline \multirow{7}{*}{} & Chest infection & 52 & 78.8 \\
\cline { 2 - 4 } & $\begin{array}{l}\text { Post-surgical } \\
\text { procedure }\end{array}$ & 6 & 9.1 \\
\cline { 2 - 4 } & Sepsis & 2 & 3.0 \\
\cline { 2 - 4 } & $\begin{array}{l}\text { Urinary tract } \\
\text { infection }\end{array}$ & 4 & 6.1 \\
\cline { 2 - 4 } & Endocarditis & 1 & 1.5 \\
\cline { 2 - 4 } & Otitis media & 1 & 1.5 \\
\hline \multirow{2}{*}{$\begin{array}{c}\text { Concomitant } \\
\text { antibiotics }\end{array}$} & Penicillin & 42 & 63.6 \\
\cline { 2 - 4 } & Cephalosporin & 24 & 36.4 \\
\hline
\end{tabular}

Furthermore, all patients received IV penicillin or cephalosporin in addition to genta. Renal function was monitored by measuring serum creatinine, (S. Cr) \& blood urea nitrogen (BUN). Although reporting adverse effects were beyond the scope of this study, no mortality, or serious adverse effects to genta were documented. Few patients showed mild elevation of S. Cr (within 10\% of baseline level) although they have a therapeutic genta level.

Subsequently, the patients are further subdivided into two groups according to their ages, for pharmacokinetic analysis. Group 1: infants (1-12 months) \& group 2: children (13144 months).

Data of determining (actual) peak and trough genta levels and the estimated PK parameters are presented in tables $3 \& 4$, respectively. Only $35 \%$ of the patients showed a peak genta level within the reference range $(6-12 \mathrm{ug} / \mathrm{ml})$. The incidence of low peak genta level was higher in infants compared to children. The mean trough genta level in both groups is potentially toxic $(>1 \mathrm{ug} / \mathrm{ml}$.).

Table 3: Genta plasma level in pediatric patients, TID regimen $(n=66)$.

\begin{tabular}{|c|c|c|c|c|}
\hline \multirow{3}{*}{ Peak } & & Level ug/ml & No & $\%$ \\
\cline { 2 - 5 } & Within range & $6-12$ & 23 & 34.8 \\
\hline \multirow{3}{*}{ Trough } & Subtherapeutic & $<6$ & 43 & 65.2 \\
\cline { 2 - 5 } & Within range & $<1$ & 64 & 97.0 \\
\cline { 2 - 5 } & Potentially toxic & $>1$ & 2 & 3.0 \\
\hline
\end{tabular}

* Ref range for multiple daily dosing: peak $6-12 \mathrm{ug} / \mathrm{ml} \mathrm{L}$, Trough $<1 \mathrm{ug} / \mathrm{ml}$ 
Table 4: Estimated PK parameters of genta in pediatric patients (Mean \pm SD).

\begin{tabular}{|l|c|c|c|c|c|c||}
\hline & \multirow{2}{*}{$\begin{array}{c}\text { Dose } \\
\mathrm{mg} / \mathrm{kg}\end{array}$} & \multicolumn{2}{|c|}{ Peak level (ug/ml) } & \multirow{2}{*}{$\begin{array}{c}\text { Trough } \\
\text { ug/ml }\end{array}$} & $\begin{array}{c}\mathrm{Vd} \\
\mathrm{L} / \mathrm{Kg}\end{array}$ & $\mathrm{t}_{1 / 2}(\mathrm{hr})$. \\
\hline Infants: $(1-12 \mathrm{~m}, n=24)$ & $2.47 \pm 1.1$ & $10.8 \pm 2.99$ & $56 \%$ & $1.7 \pm 0.84$ & $0.51^{*} \pm 0.18$ & $2.8 \pm 0.6$ \\
\hline Children:(13-144, m., $n=42)$, & $2.2 \pm 0.46$ & $12.02 \pm 2.53$ & $38 \%$ & $1.29 \pm .93$ & $0.37 \pm 0.13$ & $2.6 \pm 0.8$ \\
\hline
\end{tabular}

a: Reference range $(\mathrm{ug} / \mathrm{ml}$ ) for gentamicin, TID regimen the peak 6-12, trough $<1$

$*$ Significantly higher, t-test, $p<0.05$.

It was observed that $\mathrm{Vd}(\mathrm{L} / \mathrm{Kg})$ is relatively higher in infants $(0.51 \pm 0.18)$ compared to children $(0.37 \pm 0.13)(p<0.05)$. Figure 1 shows the simulation of genta level assuming BID, TID, OD regimen in children. It is noteworthy that the BID regimen is likely to provide higher peak \& lower trough levels compared to the TID regimen. In contrast, once-daily dosing provided a higher peak level (about $20 \mathrm{ug} / \mathrm{ml}$ ), but prolonged very low trough level $(<1 \mathrm{ug} / \mathrm{ml}$; more than $8 \mathrm{hr}$.) i.e., exceeds the time for the post-antibiotic effect of gentamicin ${ }^{14}$.

\section{Discussion}

TDM and clinical PK are valuable tools to optimize the use of genta in clinical settings ${ }^{15}$. Taking into account (PK) and pharmacodynamic (PD) properties of genta, the achievement of high peak (8-10 times MIC) and very low trough (6-8 hr.) is an empirical guide for its optimal dosing ${ }^{16}$.

The approach of using high dose and long dosing interval of $A G$ was based on two fundamental PD characteristics of this class of antibiotics: The $1^{\text {st }}$ is the post-antibiotic effect (PAE) which practically means continued bactericidal effect regardless of undetectable serum drug level for the specified time (about 3-8 hrs.).

PAE is restricted to certain strains of bacteria (gram-negative bacilli) and requires a normal immune system of the patient. In this context, for example, the duration of the PAE is reduced in the absence of polymorphonuclear leukocytes (PMNs). The $2^{\text {nd }} \mathrm{PD}$ characteristic of $A G$ is the concentration-dependent efficacy, i.e. achievement of high serum peak concentrations (8-10 higher relative to the organism's MIC) likely to be associated with higher antibacterial efficacy (more rapid, and a higher percentage of bactericidal effect $)^{14}$.
Interestingly, a PK/PD modelling study based on retrospective data of genta suggested that once-daily dosing of $5-6 \mathrm{mg} / \mathrm{kg} / \mathrm{dose}$ is adequate only to treat infections with gramnegative organisms having minimal inhibitory concentration less than $1 \mu \mathrm{g} / \mathrm{mL}$ but highlights the need to assess the safety of higher doses of genta in paediatrics ${ }^{17}$. Dose guidelines for OD aminoglycoside for pediatric patients without cystic fibrosis have been suggested given age as follows: 3 months to less than 2 years, 9.5

$\mathrm{mg} / \mathrm{kg} ; 2$ years to less than 8 years, 8.5 $\mathrm{mg} / \mathrm{kg}$; and $8-18$ years, $7 \mathrm{mg} / \mathrm{kg}^{18}$.

However, the OD regimen in paediatrics was not adopted as a universal concept and some queries need to be answered. The available evidence demonstrates that efficacy, and probable nephrotoxicity are at least equivalent between $\mathrm{OD}$ and multiple dailydosing regimens. More importantly, however, it identifies gaps in our knowledge about (1) the incidence of ototoxicity, (2) the appropriate dose (which varied from 4 to $7.5 \mathrm{mg} / \mathrm{kg}$ per 24 hours in the included trials) ${ }^{7}$.

Furthermore, A wide inter-patient variation in genta elimination and $\mathrm{Vd}$ has been recognized. Several patient-specific variables are related to elimination and therapy influence serum level. These include renal function, age, fever, lean body weight, and route of administration ${ }^{19-23}$. Pediatric patients showed higher $\mathrm{Vd}$ which implies that a high aminoglycoside dose is required to attain adequate peak levels ${ }^{24 \& 25}$. A comprehensive review of studies relevant to PK of genta in paediatrics indicated that the mean estimated genta $\mathrm{Vd}$ for newborns, infants, and children are $0.475,0.35$, and $0.33 \mathrm{~L} / \mathrm{kg}$, respectively. Although body composition and kidney maturation are identified as the main variables affecting the PK of genta in paediatrics. The authors emphasize to study the impact of other covariates, such as lean body weight, 
concomitant medication, fever, and critical illness on aminoglycoside $\mathrm{PK}^{24}$.

In the present study, the TID regimen (namely $2-2.5 \mathrm{mg} / \mathrm{kg} / 8 \mathrm{hrs}$. slow IV infusion 30 $\mathrm{min}$, rate $=$ dose $\mathrm{mg} / \mathrm{kg} /$ infusion time), automated infusion pump was utilized for pediatric patients enrolled in the study. Pediatric patients are known to have a higher ratio of body water relative to adults. About $70 \%$ of the bodyweight of term infants is water compared to $65 \%$ or $60 \%$ in children, and adolescents respectively ${ }^{26}$. Genta is a very polar drug, and its distribution is confined to extracellular fluids ${ }^{27}$. Given this low peak, genta levels are expected in a traditional dosing regimen $2.5 \mathrm{mg} / \mathrm{kg} / 8 \mathrm{hrs}$. In the present study, there was an obvious relationship between high $\mathrm{Vd}$ and the high incidence of the low peak genta level. Patients with low peak levels of genta are common in clinical practice ${ }^{28 \& 29}$. Genta is mainly eliminated by renal clearance so that it has a shorter half-life in children with normal renal function ${ }^{27}$. In the present study, the mean half-life of genta is about $3 \mathrm{hr}$. and not affected by the age of patients.
Many programs that use PK and simulations are of paramount importance to adjust the therapeutic regimen for drugs with a narrow therapeutic range. For example, AG, optimal software guide optimal dosing on an

individual basis based on an integration between the patient's profile (renal function, age, etc.); PD (e.g., post-antibiotic effect), and PK [e.g. Vd, k]. Moreover, it allows $r$ estimation of individual PK parameters based on the measured drug levels. These data support design of optimal dosing regimen on an individual basis, i.e to achieve a target peak and trough AG levels ${ }^{30}$.

In the present study, we used a simple Excel-based program to simulate various regimens given a pilot sample of pediatric patients who received genta but do not suffer other chronic diseases or renal impairment (supplementarily material).

Given the present results of high $\mathrm{Vd}$ and short half-life, PK simulation suggests 3.5-4 $\mathrm{mg} / \mathrm{kg}$ BID. instead of 2-2.5 mg TID. (Fig 1). OD regimen provided a higher genta peak but prolonged a very low trough level.

\section{Simulation of gentamicin level in pediatric patients}

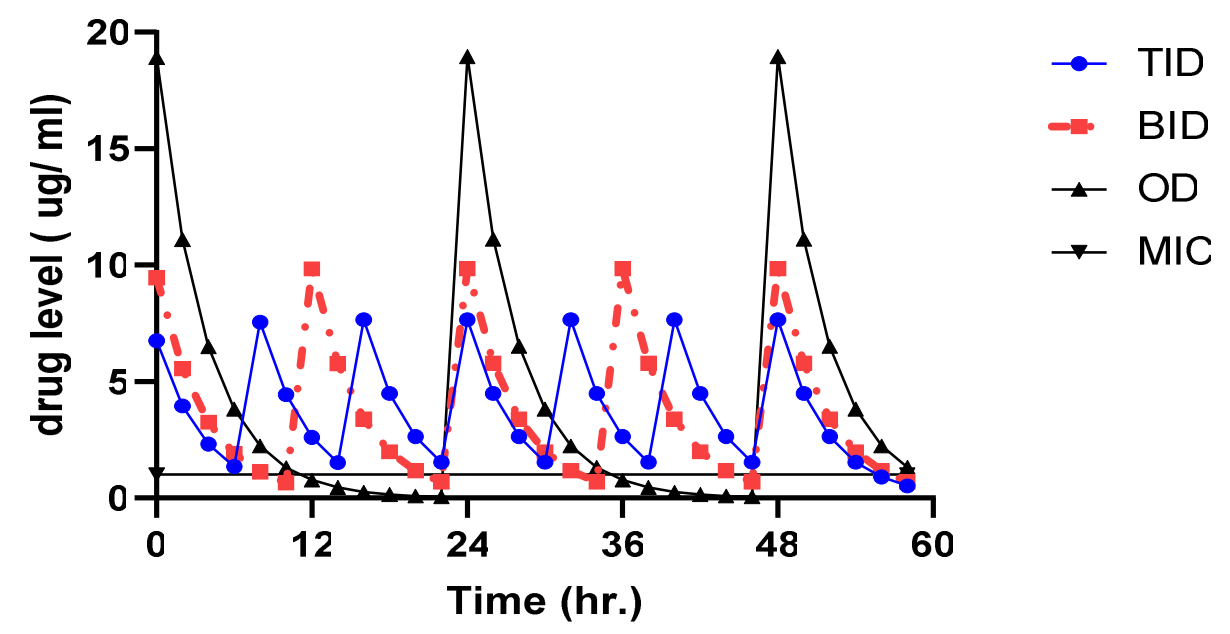

Fig. 1: Simulation of genta level at steady state after repeated IV infusion in Children ( $>1-12 \mathrm{y})$ in view of mean volume of distribution: $0.37 \mathrm{~L} / \mathrm{kg}$, half-life: $2.6 \mathrm{hr}$.), $2.5 \mathrm{mg} / \mathrm{kg}$, TID, $3.5 \mathrm{mg} / \mathrm{kg}$ BID and OD $7 \mathrm{mg} / \mathrm{kg}$.

The minimal inhibitory concentration of genta-sensitive bacteria (MIC) was supposed to be $1 \mathrm{ug} / \mathrm{ml}$, optimal efficacy peak 10 times MIC. Recall the time of trough level < MIC, should not excessed 8-10 hr. (post-antibiotic effect). [see discussion for details]. 
The incidence of acute kidney injury (AKI) induced by AG in children was reported as $20-33 \%^{31}$. In the present study, nephrotoxicity due to genta was not documented and no clear association between genta serum levels and $\mathrm{S}$. $\mathrm{Cr}$ levels was observed. Ali et al., documented that $\mathrm{S}$. $\mathrm{Cr}$ is a poor biomarker to follow the renal function in preterm neonates administer genta ${ }^{32}$. Marked elevation of $\mathrm{S}$. Cr above its normal values is not significantly noticed until about $25-50 \%$ of kidney function has deteriorated. Therefore, using this biomarker alone to monitor kidney function means that the detection of nephrotoxicity may be late and may underestimate drug-induced nephrotoxicity $^{33 \& 34}$. Therefore, a more accurate renal function biomarker was suggested as a better early marker of drug-induced renal injury e.g., serum cystatin $\mathrm{C}$; and $\beta 2$-microglobulin ${ }^{35}$. Kidney injury molecule-1 was suggested as an early biomarker to identify AG-induced proximal tubular injury with promising results in clinical studies ${ }^{36}$. Cochlear toxicity of AG is less common in neonates and children compared to adults, the reported incidence was about $2 \%$ in neonates ${ }^{37}$.

\section{Conclusion}

Given the PK parameters in the present study, the TID of $2-2.5 \mathrm{mg} / \mathrm{kg}$ is not likely to provide an adequate peak level in most pediatric patients with normal renal function. BID (e.g., 3.5-4 mg/kg) is more convenient and supposed to produce therapeutic gent levels. The Excel sheet was provided in the supplementary material to allow predication of other dosing regimens.

\section{Acknowledgement}

This study was supported by a grant from the dean of research at King Abdulaziz University. The authors would like to thank Prof Abdulrahman Al-Ahdal, Faculty of Pharmacy; Dr Nadia M. Fida \& Dr Mohammed Fadul-Allah Farooq, Dept. of paediatrics king Abdu-Aziz University for their assistance and support in this study.

\section{Supplementary materials}

PK-Simulation (software) for education \& research purpose only. https://drive.google.com/file/d/1-

Vv2JDvQB3K-

v5mwa_3ozvtTW0YlpGbP/view?usp=sharing

\section{Disclaimer}

The medical information and trends in this research are not intended to change any protocols and have not been evaluated clinically.

\section{REFERENCES}

1. P. Saleh, S. Abbasalizadeh, S. Rezaeian, M. Naghavi-Behzad, et al., "Gentamicinmediated ototoxicity and nephrotoxicity", A Clinical trial Study, Niger. Med. J., 57 (6), 347-352 (2016).

2. A. J. Heffernan, F. B. Sime, F. S. Taccone and J. A. Roberts, "How to optimize antibiotic pharmacokinetic / pharmacodynamics for Gram-negative infections in critically ill patients", Curr. Opin. Infect. Dis., 31 (6), 555-565 (2018).

3. S. Kadomura, "Therapeutic Drug Monitoring of Antimicrobial Agents", Rinsho. Byori., 64 (12), 1367-1372 (2016).

4. C. Mabilat, M. F. Gros, D. Nicolau, J. W. Mouton, et al., "Diagnostic and medical needs for therapeutic drug monitoring of antibiotics", Eur. J. Clin. Microbiol. Infect. Dis., 39 (5), 791-797 (2020).

5. B. Zylbersztajn, M. Barraza, J. P. Torres and J. Morales, "Therapeutic monitoring of antimicrobial agents in pediatrics. Review based on Latin American experiences", Rev. Chilena. Infectol., 35 (1), 22-28 (2018).

6. S. M. Plajer, P. K. Chin, J. W. VellaBrincat, P. J. Buffery, et al., "Gentamicin and renal function: Lessons from 15 years' experience of a pharmacokinetic service for extended interval dosing of gentamicin", Ther. Drug Monit., 37 (1), 98-103 (2015).

7. E. J. Best, M. Gazarian, R. Cohn, M. Wilkinson, et al., "Once-daily gentamicin in infants and children: A prospective cohort study evaluating safety and the role of therapeutic drug monitoring in minimizing toxicity", Pediatr. Infect. Dis. J., 30 (10), 827-832 (2011). 
8. M. Zakova, S. Pong, A. Trope, E.G Atenafu, et al., "Dose derivation of oncedaily dosing guidelines for gentamicin in critically ill pediatric patients", Ther. Drug Monit., 36 (3), 288-294 (2014).

9. R. Brigg Turner, F. Elbarbry and L. Biondo, "Pharmacokinetics of once and twice daily dosing of intravenous tobramycin in paediatric patients with cystic fibrosis", J. Chemother., 28 (4), 304-307 (2016).

10. Medscape, "Gentamicin", 2020, cited 20205 March, Available from, https://reference.medscape.com/drug/gent ak-garamycin-gentamicin-342517

11. H. Lu and S. Rosenbaum, "Developmental pharmacokinetics in pediatric populations", J. Pediatr. Pharmacol. Ther., 9 (4), 262-76 (2014).

12. A. F. Mohamed, E. I. Nielsen, O. Cars and L. E. Friberg, "Pharmacokineticpharmacodynamic model for gentamicin and its adaptive resistance with predictions of dosing schedules in newborn infants", Antimicrobial Agents and Chemotherapy, 56 (1), 179-188 (2012).

13. L. Shargel and Y. Andrew, "Applied biopharmaceutics and pharmacokinetic", Appelton \& Lange, (1993).

14. UPTODATE.com. "Dosing and adminsteraion of aminoglycosides", 2020 March 2021, Jan 2020, Available from, https://www.uptodate.com/contents/dosin g-and-administration-of-parenteralaminoglycosides/print?search=gentamicin \&topicRef $=483 \&$ source $=$ see_link.

15. K. M. Krause, A. W. Serio, T. R. Kane and L. E. Connolly, "Aminoglycosides: An Overview", Cold Spring Harb. Perspect. Med., 6 (6), (2016).

16. D. P. Nicolau, C. D. Freeman, P. P. Belliveau, C. H. Nightingale, et al., "Experience with a once-daily aminoglycoside program administered to 2,184 adult patients", Antimicrob. Agents Chemother., 39 (3), 650-655 (1995).

17. A. Alsultan, M. Abouelkheir, Y. Elsharawy, A. Alkoraishi, et al., "Optimizing Gentamicin Dosing in Pediatrics Using Monte Carlo Simulations", Pediatr. Infect. Dis. J., 38 (4), 390-395 (2019).
18. E. J. McDade, J. L. Wagner, B. S. Moffett and D. L. Palazzi, "Once-daily gentamicin dosing in pediatric patients without cystic fibrosis", Pharmacotherapy, 30 (3), 248253(2010).

19. . A. Bijleveld, T. R. de Haan, H. J. van der Lee, F. Groenendaal, et al., "Altered gentamicin pharmacokinetics in term neonates undergoing controlled hypothermia", Br. J. Clin. Pharmacol., 81 (6), 1067-1077 (2016).

20. C. J. Hodiamont, J. M. Janssen, M. D. de Jong, R. A. Mathôt, et al., "Therapeutic Drug Monitoring of Gentamicin Peak Concentrations in Critically Ill Patients", Ther. Drug Monit., 39 (5), 522-530 (2017).

21. C. J. Hodiamont, N. P. Juffermans, C. S. Bouman, M. D. de Jong, et al., "Determinants of gentamicin concentrations in critically ill patients: A population pharmacokinetic analysis", Int. J. Antimicrob. Agents, 49 (2), 204-211 (2017).

22. C. Johnston, S. N. Hilmer, A. J. McLachlan, S. T. Matthews, et al., "The impact of frailty on pharmacokinetics in older people: Using gentamicin population pharmacokinetic modeling to investigate changes in renal drug clearance by glomerular filtration", Eur. J. Clin. Pharmacol., 70 (5) 549-555 (2014).

23. S. E. Medellín-Garibay, A. RuedaNaharro, S. Peña-Cabia, B. García, et al., "Population pharmacokinetics of gentamicin and dosing optimization for infants", Antimicrob. Agents Chemother., 59 (1) 482-489(2015).

24. M. Crcek, J. Zdovc and M. Kerec Kos, "A review of population pharmacokinetic models of gentamicin in paediatric patients", J. Clin. Pharm. Ther., 44 (5), 659-674 (2019).

25. H. Wang, C. Sherwin, J. V. S. Gobburu and V. Ivaturi, "Population Pharmacokinetic Modeling of Gentamicin in Pediatrics", J. Clin. Pharmacol., 59 (12), 1584-1596 (2019).

26. G. F. López-Sánchez, M. Sgroi, S. D’Ottavio, A. Díaz-Suárez, et al., "Body composition in children and adolescents residing in Southern Europe: Prevalence of overweight and obesity according to 
different international references", Frontiers in Physiology, 10 (130), (2019).

27. DRUGBANK, "Gentamicin", 2021, cited 202117 february, Available from: https://go.drugbank.com/drugs/DB00798.

28. C. Roger, B. Nucci, B. Louart, A. Friggeri, et al., "Impact of $30 \mathrm{mg} / \mathrm{kg}$ amikacin and $8 \mathrm{mg} / \mathrm{kg}$ gentamicin on serum concentrations in critically ill patients with severe sepsis", $\boldsymbol{J}$. Antimicrob. Chemother., 71 (1), 208-212 (2016).

29. C. Roger, B. Nucci, N. Molinari, S. Bastide, et al., "Standard dosing of amikacin and gentamicin in critically ill patients results in variable and subtherapeutic concentrations", Int. J. Antimicrob. Agents, 46 (1), 21-27 (2015).

30. R. Jelliffe, "Using the BestDose Clinical Software-Examples With Aminoglycosides, in Individualized Drug Therapy for Patients", R. W. Jelliffe and M. Neely, Eds., Chapter 6, Academic Press: Boston, 2017, pp. 59-75.

31. M. Zappitelli, B. S. Moffett, A. Hyder and S.L. Goldstein, "Acute kidney injury in non-critically ill children treated with aminoglycoside antibiotics in a tertiary healthcare centre: A retrospective cohort study", Nephrol. Dial. Transplant., 26 (1), 144-150 (2011).
32. A. S. Ali, M. F. Farouq and K. A. AlFaify, "Pharmacokinetic approach for optimizing gentamicin use in neonates during the first week of life", Indian Journal of Pharmacology, 44 (1), 36-40 (2012).

33. S. S. Waikar and J. V. Bonventre, "Creatinine kinetics and the definition of acute kidney injury", J. Am. Soc. Nephrol., 20 (3), 672-679 (2009).

34. D. J. Askenazi, N. Ambalavanan and S. L. Goldstein, "Acute kidney injury in critically ill newborns: What do we know? What do we need to learn?, Pediatr. Nephrol., 24 (2), 265-274 (2009).

35. B. R. Griffin, S. Faubel and C. L. Edelstein, "Biomarkers of Drug-Induced Kidney Toxicity", Therapeutic Drug Monitoring, 41 (2) 213-226 (2019).

36. S. J. McWilliam, D. J. Antoine, R.L. Smyth and M. Pirmohamed, "Aminoglycoside-induced nephrotoxicity in children", Pediatric Nephrology (Berlin, Germany), 32 (11), 2015-2025 (2017).

37. G. J. Matz, "Aminoglycoside cochlear ototoxicity", Otolaryngologic Clinics of North America, 26 (5), 705-712 (1993). 


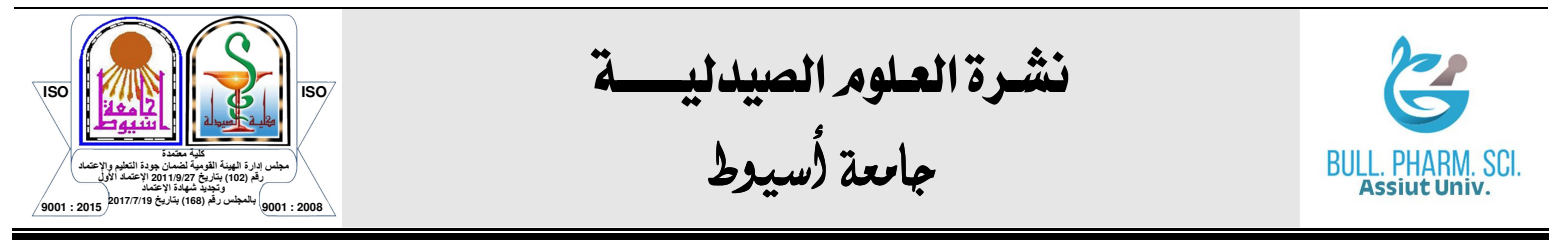

\title{
محاكاة الحركة الدو ائية للجنتاميسن في الأطفال واقتراح نظام الجرعات الامثل
}

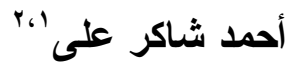 \\ 'قسم الصيدلانيات ، كلية الصيدلة ، جامعة أسيوط ، أسيوط ، مصر
}

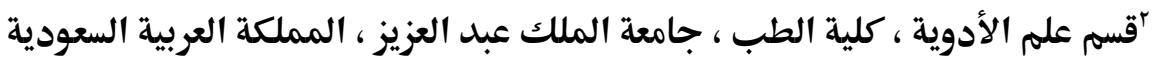

الاهداف: أجريت هذه الدراسة الاستطلاعيه لتحسين استخدام الجنتاميسين في الأطفال بالاعتمــاد علـىى

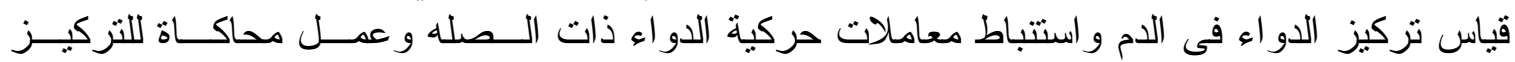

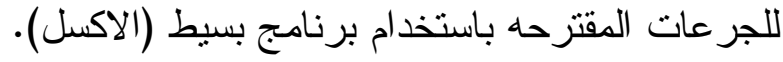

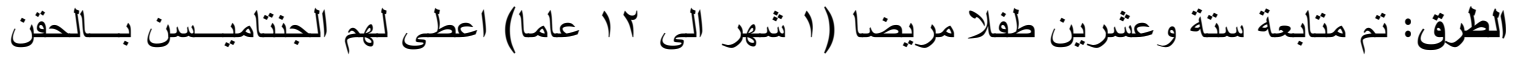

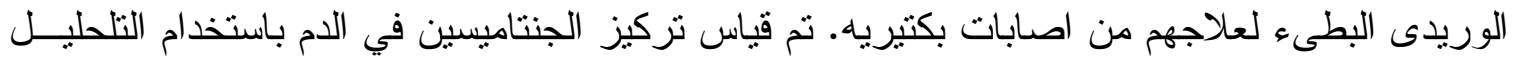

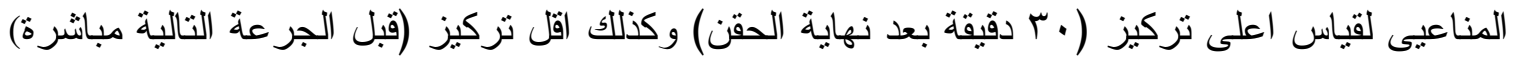

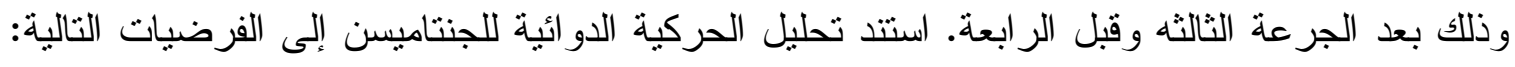

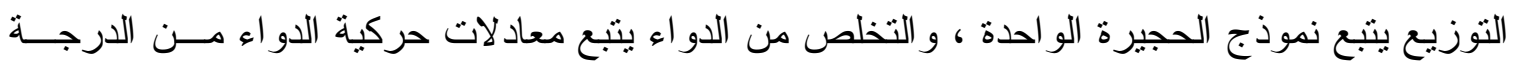

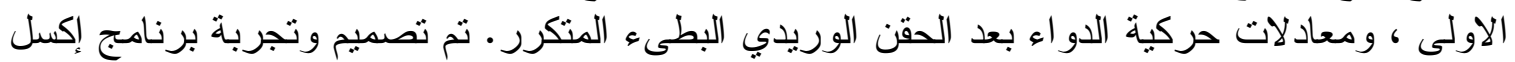

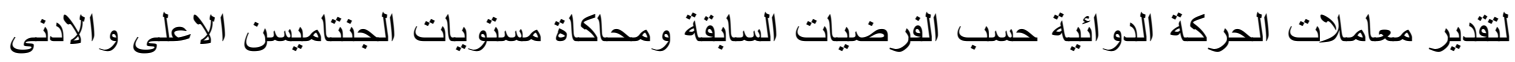

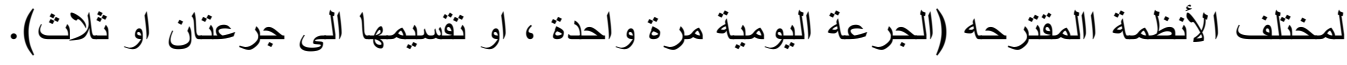

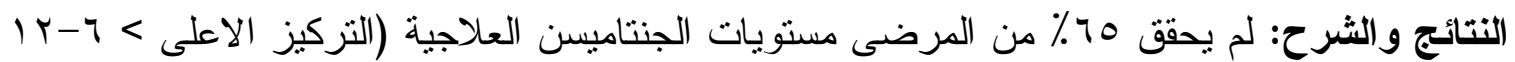

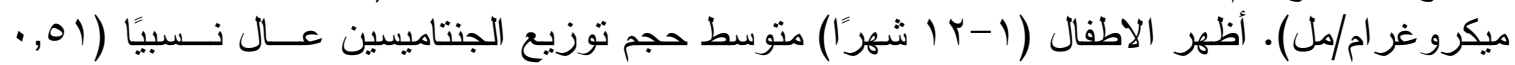

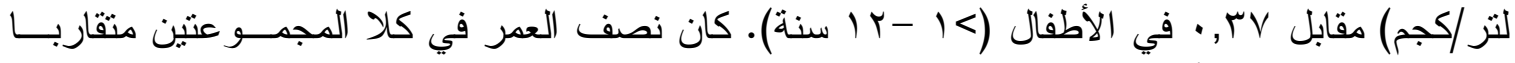

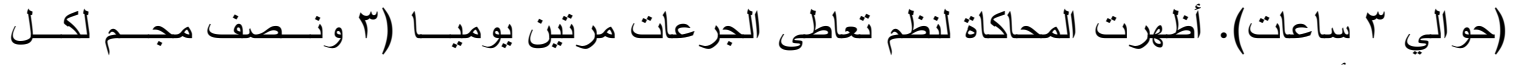

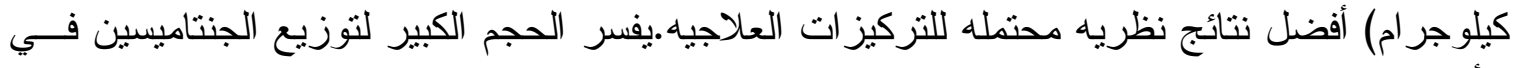

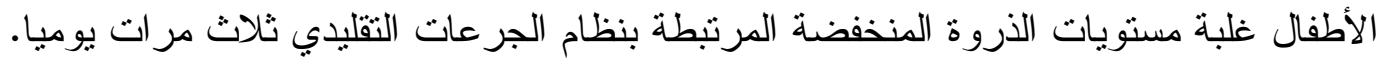
الخلاصة: قياس مستوى الجنتاميسين فى الدم ، و استتباط معاملات حركية الدو اء ، و المحاكاة للتركيز ات

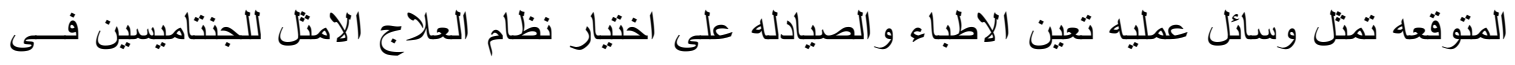

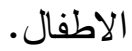

